\title{
ON THE MACROSCOPICAL RICKETTSIA AGGLUTINATION TEST ON THE HOLLOW SLIDE-GLASS
}

\author{
By Masami KITAOKA and Hiromasa INOUE \\ The National Institute of Health of Japan, Tokyo \\ (Received for publication Sept. 20, 1950)
}

Since it was revealed that the causative agent for the murine and epidemic typhus, scrub typhus, Rocky Mountain Spotted fever, trech fever and other diseases of similar character were all of rickettsial diseases, an attempt has been made to establish the agglutination test with each homologous rickettsia as an antigen not only for the specific diagnosis $(1,2)$ and differentiation $(3,4)$ but also for the study on the antigenic strusture $(3,5)$ of each rickettsia.

In earlier days, the antigen for rickettsia agglutination test (R.A.T.) was prepared from the following materials, emulsion of eggs (1) from the infected ticks with Rickettsia (R.) rickettsii, each emulsion of the intestines $(2,3,5,7,8)$ of the infected lice with each R. prowazekii, R. typhi and R. quintana, peritoneal washing (7) of the white rats infected with typhus fever, suspension of slide cell culture (10) with R. prowazekii, and emulsion of infected lung tissue $(9,11,19)$ of mice or rats with typhus fever. And the judgement was made under microscope $(1,2,4,14,16)$ on the preparates stained by Giemsa's solution. However it was noted that these methods did not afford a satisfactory result.

In 1932, Zinsser (3) has designed a special capillary test-tubes charged with $0.025 \mathrm{cc}$. each of the antigen and the test serum placed in a water bath at $40^{\circ} \mathrm{C}$. for 2 to 5 hours and left standing in an ice-chamber overnight for inspection by naked eyes on the agglutination. Since then such process $(4,5,7,8)$ and modified method (11) have been in practice by workers in despite of much difficulties in preparation of the antigen before Cox (6) has, in 1938, published of his yolk sac culture method to result in an abundant harvest much easily of pure rickettsia-body.

The remarkable progress has thus been made in R.A.T. when Plotz (12) reported of the method of reading macroscopically the agglutination of rickettsia antigen prepared by Cox-Craigie's method, namely, $0.25 \mathrm{cc}$. of the antigen mixed with the same amount of the serum to be tested in test-tubes in the way similar to the Widal's test with Salmonella typhi, incubated at $42^{\circ} \mathrm{C}$. for 4 hours and left standing in an icechamber $\left(4^{\circ} \mathrm{C}\right)$ for 16 to 18 hours and then read by naked eyes. This method requires too much amount of the antigen to be in practice generally by the physician, therefore, a simplified orientating method on slide-glasses with a loopful amount of the antigen was recommended by Fitz-Patrick (21), Castaneda (9) and Kitaoka (20).

Furthermore the attempt was made by us to quantitative estimations of R.A.T. with each two-fold dilution of the test serum by mixing with the equal amount of the antigen as minimal as a drop on a hollow slide-glass and read the result by naked eyes to differentiate the typhus fever group from the other acute infectious diseases, as 
well as the epidemic typhus from the murine.

\section{Equipments and UTENSILS :}

(1) Several pipettes adjusted with its point to make up $1.0 \mathrm{cc}$. of saline water with some 20 to 25 drops. (2) Slide-glass with the 4 hollows. One hollow is $1-2 \mathrm{~cm}$. in diameter and $0.5 \mathrm{~cm}$. deep in the centre. (3) An illuminator. (4). An incubator adjusted to $37^{\circ} \mathrm{C}$. (5) A refrigerator.

\section{Technique :}

Differentiation of the epidemic typhus from the murine.

1). Two sets of two slide glasses mentioned above are ready and each hollow on the slide-glass is numbered No. 1 to No. 8 in each row as shown in the figure.

(1) (2) (3) (4)

First row

Second row

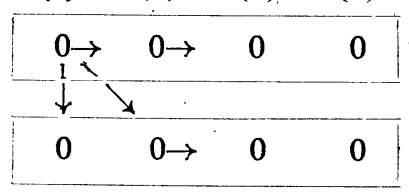

\begin{tabular}{cccc}
\hline$(5)$ & $(6)$ & $(7)$ & $(8)$ \\
\hline 0 & 0 & 0 & 0 \\
\hline 0 & 0 & 0 & 0 \\
\hline
\end{tabular}

2). Physiological saline water ( $\mathrm{pH} 7.0$ ) is placed by the pipette mentioned above in each hollow, 9 drops in No. 1 of the first row and one drop to each of all the other hollows excepting No. 1 of the 2 nd row which should remain empty then.

3). One drop of the serum to be tested is placed by the pipette to No. 1 of the first row, thoroughly mixed to $1: 10$ dilution.

4). One drop of such diluted serum is placed by the same pipette to each No. 1 of the 2 nd row and No. 2 of the both rows.

5). Further dilution of the serum is carried out by transfering a drop pipetted from one to the other in two-fold dilution starting from No. 2 till No. 7, then the serum in No. 1 to No. 7 is so diluted as to $1: 10,1: 20,1: 40,1: 80,1: 160,1: 320$ and $1: 640$ respectively. The last one (No. 8) is left for the control without the serum.

6). One drop of the epidemic typhus antigen or the murine is added to each of all the hollows on the first row or the 2 nd respectively. The antigenicity of each antigen is to be estimated prior to practice. The serum in each hollow No. 1 to No. 7 on either rows is diluted $1: 20$ to $1: 1280$ respectively.

7). Contents of the hollows are throughly mixed by shaking the salines. The hollow slide-glass with contents is covered with another unused one to avoid evapolation from the contents and put in an incubator at $37^{\circ} \mathrm{C}$. for 6 hours and then left standing overnight in the refrigerator at $4-10^{\circ} \mathrm{C}$. The result is to be read by naked eyes by the aid of the illuminator down below.

8). The agglutination phenomenon is more easily read by naked eyes by simply placing the slides on a sheet of white paper instead of being illuminated down below when methylen blue or gentian violet is added to the antigen to be used.

9). Reading: Homogeneously turbid similar to the control (0); doubtfully agglutinated ( \pm ); undoubtedly agglutinated fine (1); distinct agglutination with the sur- 
roundings remaining somewhat turbid (2) and distinct agglutination in the clear ground (3); a little less than (2) grade is signed as (2-) and more than (2) shall be considered: positive.

\section{EXPERIMENTS}

This method of R.A.T. has been recommended on the basis of the following funda-mental experiments.

1). Influence upon R.A.T. of temperature and duration of time. Macroscopical R.A.T. is observed in each incubator at $42^{\circ} \mathrm{C}, 40^{\circ} \mathrm{C}, 37^{\circ} \mathrm{C}$ and the room temperature. for a period of $2 \sim 5$ and 24 hours. Our R.A.T. on the hollow slide-glasses were also. observed at the room temperature $\left(12^{\circ} \mathrm{C}\right), 32^{\circ} \mathrm{C}, 37^{\circ} \mathrm{C}$ and $42^{\circ} \mathrm{C}$ and watched continually when the agglutination developed (Table 1 ).

Table 1

Influence upon R. A.T. of temperature and duration of time

\begin{tabular}{|c|c|c|c|c|c|c|c|c|c|c|c|c|c|c|c|c|c|c|c|c|}
\hline Hours & \multicolumn{4}{|c|}{2} & \multicolumn{4}{|c|}{3} & \multicolumn{4}{|c|}{4} & \multicolumn{4}{|c|}{6} & \multicolumn{4}{|c|}{$\begin{array}{l}\text { overnight in } \\
\text { refrigerator }\end{array}$} \\
\hline $\begin{array}{l}\text { serum } \\
\text { dilution }\end{array}$ & 1:80 1:1 & \multicolumn{3}{|c|}{$1601: 3201: 640$} & \multicolumn{4}{|c|}{ 1:80 1:160 1:320 1:640 } & \multicolumn{4}{|c|}{ 1:80 1:160 1:320 1:640 } & \multicolumn{4}{|c|}{$1: 801: 1601: 3201: 640$} & \multicolumn{4}{|c|}{ 1:80 1:160 1:320 1:640. } \\
\hline \multicolumn{21}{|l|}{ Temperature } \\
\hline $\begin{array}{l}\text { room temp. } \\
\quad\left(12^{\circ} \mathrm{C}\right)\end{array}$ & & 24 & hrs. & & & & & & & & & & & & & & & 0 & 0 & 0 \\
\hline $32^{\circ} \mathrm{C}$ & 0 & 0 & 0 & 0 & 1 & 0 & 0 . & 0 & 1 & 1 & 0 & 0 & 1 & 1 & \pm & 0 & 2 & 2 & 1 & 0 \\
\hline $32^{\circ} \mathrm{C}$ & & 24 & ars. & & & & & & & & & & & & & & 3 & 2 & 2 & 0 \\
\hline $37^{\circ} \mathrm{C}$ & 1 & 0 & 0 & 0 & 2 & 1 & 0 & 0 & 2 & 1 & 0 & 0 & 3 & 2 & 1 & 0 & 3 & 2 & 2 & 0 \\
\hline $42^{\circ} \mathrm{C}$ & 1 & 0 & 0 & 0 & 2 & 1 & \pm & 0 & 2 & 1 & \pm & 0 & 3 & 2 & 2 & 0 & 3 & 3 & 2 & 0 \\
\hline
\end{tabular}

antigen: R. prowazekii, Convalescent serum from the epidemic typhiss case $1: 320$

It was seen that the reaction appeared most early and completed at the end of 6 . hours at the temperature of $42^{\circ} \mathrm{C}$ while incompleted even for 6 hours and required to be left standing overnight in a refrigerator when the hollow slide-glass has been placed at the temperature of $37^{\circ} \mathrm{C}$. At the lower temperatures than $32^{\circ} \mathrm{C}$ the reaction appeared much later and required 24 hours to complete the reaction at $32^{\circ} \mathrm{C}$ and, it was found failing even after 24 hours at $12^{\circ} \mathrm{C}$. It is generally difficult at present in Japan to equip a laboratory with another incubator adjusted to $42^{\circ} \mathrm{C}$. Well it is recommended to follow the process first by incubating the slides at $37^{\circ} \mathrm{C}$ for 6 hours and then by leaving them to stand overnight at $4-10^{\circ} \mathrm{C}$. But when it is in an emergency the method of 6 hours at $42^{\circ} \mathrm{C}$ is preferably used.

2). Certainty in the reaction by our method;

The method described above in order to utilize the minimal amount of both antigen and serum seems somewhat uncertain in comparison with usual test-tube process and the experimental error may be thought larger in our method:

But it has become clear that there is no noticeable difference between both results estimated by one method and the a nother with interval of several days on the same test serum. 
3). Specificity in reaction;

There are many reports concerning the specificity in R. A. T. especially its relation to Weil-Felix reaction and complement fixation teast (C.F.T.). The former is said appearing much earlier than the agglutination test (Fitz-Patrick (10), Hudson (11) and Hammarström (14)) or is observed appearing rather later (Plotz (12), Nelson (13) and Addison (15)) and is though occuring simultaneously (Castaneda (5,9), Packalin (16) and Giroud (17)). There is no definite opinion about this point because the Weil-Felix reaction may not be specific for the typhus fever. R.A.T. is said appearing much earlier than C.F. T. (Plotz (12), Nelson (13) and Addison (15)) and is said more specific than C.F.T. (Nelson (13)) or almost the same (Castaneda (9)), Packalin (16) and Plotz (18)).

Our method of R.A.T. described above is specific and is capable of differentiating the typhus fver group from various other acute infectious diseases and also the epidemic typhus from the murine. The reaction is found appearing almost simultaneously, if not a little later, with Weil-Felix reaction and appears undoubtedly much earlier than C.F.T. as having been made clear by us by daily examinations carried out of the serum taken from a murine typhus case (Table 2).

Table 2

Serological pattern in a murine typhus case

\begin{tabular}{c|c|c|c|c|c|c}
\hline \hline \multirow{2}{*}{$\begin{array}{c}\text { Day of } \\
\text { disease }\end{array}$} & Weil-Felix & \multicolumn{2}{|c|}{ R. A. T. } & \multicolumn{2}{c}{ C. F. T. } \\
& reaction & Epidemic & $\begin{array}{c}\text { Murine } \\
\text { antigen }\end{array}$ & $\begin{array}{c}\text { Solouble } \\
\text { antigen }\end{array}$ & $\begin{array}{c}\text { Epidemic } \\
\text { antigen }\end{array}$ & $\begin{array}{c}\text { Murine } \\
\text { antigen }\end{array}$ \\
\hline 2 & & & & 0 & 0 & 0 \\
3 & 20 & & & 0 & 0 & 0 \\
6 & 20 & 0 & 0 & 0 & 0 & 0 \\
8 & 5120 & 0 & 40 & 10 & 0 & 10 \\
13 & 10210 & 20 & 40 & 40 & 20 & 80 \\
18 & 5120 & 0 & 40 & 10 & 0 & 40 \\
23 & 2560 & 0 & 20 & 0 & 0 & 40 \\
33 & 1280 & 0 & 20 & 0 & 0 & 10 \\
\hline
\end{tabular}

\section{ANTIGEN :}

1). Preparation of antigen

It is essential to provide a highly specific antigen for R.A.T. . The antigen is prepared by us from the fresh vaccine by Cox Craigie's method. The vaccine is centifugalized 6000-7000 r.p.m. for half-an- hour to an hour, or 4000 r.p.m. for 2-3 hours and the supernatant is discarded. The sediment is washed 2-3 times with phosphoric acid buffered saline at $\mathrm{pH} 7.0$ and is resuspended in $1 / 40-1 / 50$ to the original volume. As R. suspension often causes spontaneous agglutination during a period of its preservation the normal human or guinea-pig serum or gelatin is to be added in proportion of $1: 200$ to avoid the spontaneous agglutination.

2). Estimation of the antigenicity of antigen 
It is absolutely necessary to estimate the antigenicity of antigen prepared as described above with the known standard immune serum because the condensed rickettsia-body does not always serve as an antigen. Sometimes it has no antigenicity nor specific partial antigen for the epidemic typhus or the murine respectively.

Plotz (12) has described to use 10-20 units for C. F. T. in every $0.25 \mathrm{cc}$. of antigen while Castaneda (9) recommends to use an antigen effecting distinctly positive within 1-3 minutes in a preparatory test with immune rabbit serum. According to our experience a good antigen for C.F.T. is not always suitable for R.A.T. . The antigenicity of antigen for R.A.T. should be estimated in the similar way to have been indicated by us (22) in C.F.T. . If there is a known standard immune serum it is very easy to estimate the antigenicity of the antigen to be tested, namely, each two-fold dilution of the antigen is mixed with an equal amount of the standard serum containing one or two units of antibody in order to determine one unit of the antigen in practice.

If both titers of antigen as well as immune serum are unknown, the agglutination field should be drawn up in two dimension, one is a series of two-fold dilution of the immune serum and the other that of the antigen. For example if the agglutination

Table 3 (A)

Estimation of potency both of antigen and immune serum

\begin{tabular}{l|c|c|c|c|c|c|c|c}
\hline \hline \multirow{2}{*}{ Antigen } & $\begin{array}{c}\text { Serum dilution } \\
\text { Antigen } \\
\text { dilution }\end{array}$ & $1: 20$ & $1: 40$ & $1: 80$ & $1: 160$ & $1: 320$ & $1: 640$ & $1: 1280$ \\
\hline \multirow{3}{*}{ Epidemic } & $1: 1$ & 3 & 3 & 2 & 2 & 2 & 1 & 0 \\
& $1: 2$ & 3 & 3 & 2 & 2 & 2 & \pm & 0 \\
& $1: 4$ & 0 & 0 & 0 & 0 & 0 & 0 & 0 \\
\hline \multirow{3}{*}{ Murine } & $1: 1$ & 3 & 2 & 2 & 1 & 0 & 0 & 0 \\
& $1: 2$ & 2 & 2. & 1 & 0 & 0 & 0 & 0 \\
& $1: 4$ & 0 & 0 & 0 & 0 & 0 & 0 & 0 \\
\hline
\end{tabular}

A (No. J-1038): anti-epidemic typhus serum. C.F.T. titer : $1: 320$ (Epidemic); $1: 0$ (Murine)

Table 3 (B)

\begin{tabular}{l|c|c|c|c|c|c|c|c}
\hline \multirow{2}{*}{ Antigen } & $\begin{array}{c}\text { Serum dilution } \\
\text { Antigen } \\
\text { dilution }\end{array}$ & $1: 20$ & $1: 40$ & $1: 80$ & $1: 160$ & $1: 320$ & $1: 640$ & $1: 1280$ \\
\hline \multirow{3}{*}{ Murine } & $1: 1$ & 3 & 3 & 3 & 2 & 1 & 0 & 0 \\
& $1: 2$ & 3 & 2 & 2 & 2 & 0 & 0 & 0 \\
Epidemic & $1: 4$ & 1 & 0 & 0 & 0 & 0 & 0 & 0 \\
\hline & $1: 1$ & 2 & 2 & \pm & 0 & 0 & 0 & 0 \\
& $1: 2$ & 2 & 2 & 0 & 0 & 0 & 0 & 0 \\
& $1: 4$ & 0 & 0 & 0 & 0 & 0 & 0 & 0 \\
\hline
\end{tabular}

B (No. W-0): antigen murine typhus serum. C.F.T. titer: Epidemic 1:0; Murine 1:160 
titers of both immune sera A (C.F.T. titer epidemic 1:320 and murine 1:0) and B (C.F. T. titer epidemic $1: 0$ and murine $1: 160$ ) as well as the antigenicity of both epidemic and murine typhus antigens are unknown, those titers are to be estimated as shown in table 3. The immune serum is diluted up to $1: 1280$ and the antigen up to $1: 4$, dilution of $1: 320$ of $\mathrm{A}$ shows positive agglutination for $1: 1$ or $1: 2$ diluted epidemic antigen and slight cross reaction for murine antigen.

The agglutination titer of $\mathrm{A}$ is read $1: 320$ for $1: 1$ or $1: 2$ diluted epidemic antigen and the antigen unit to be used for the test is calculated from the maximum dilution of antigen proving positve R.A.T. with the minimum cross reaction on the murine typhus' with 1 or 2 units of immune serum. This epidemic antigen is to be used $1: 2$. diluted. The murine antigen shall be used 1:2 diluted from the results obtained by the method similar to the epidemic typhus antigen.

Anyway the estimation of the antigen unit for R.A.T. is not so complicated as. that for C.F.T. where 2 unit of antigen is computed by using 4 units of complement fixing antibody. A converse result was, however, obtained by R.A.T. in differentiating the epidemic typhus from the murine when the concentrated rickettsia-body suspension was simply used as antigen without estimation of its antigenicity (Table 4). It seems very likely that the murine antigen was correctly used but the epidemic was. too low. Furthermore it is difficult to read the result of R.A.T. by naked eyes when the actual number of rickettsia-body in the antigen was too less or too much. Though the actual number of rickettsia-body contained in one unit of the antigen might be. not always the same it is essential to use one unit of the antigen on one hand still carrying the partial antigen specific for the epidemic or murine typhus by which the.

Table 4

\section{R.A.T. with epidemic antigen of unknown potency}

Before estimation of antigenicity

\begin{tabular}{|c|c|c|c|c|c|}
\hline antigen $\quad$ Serum dilution & $1: 40$ & $1: 80$ & $1: 160$ & $1: 320$ & $1: 640$ \\
\hline Epidemic & 2 & 0 & 0 & 0 & 0 \\
\hline Murine & 2 & 2 & 2 & 0 & 0 \\
\hline \multicolumn{6}{|l|}{ after } \\
\hline Serum dilution & $1: 40$ & $1: 80$ & $1: 160$ & $1: 320$ & 1 i 640 \\
\hline Epidemic & 3 & 2 & 2 & 2 & 2 \\
\hline Murine & 2 & 2 & 2 & 1 & 0 \\
\hline
\end{tabular}

serum : epıdemic typhus case

differentiation each other is possible and on the other hand containing the suitable number of rickettsia-body for R.A.T. to be read by naked eyes. The antigen can well be preserved for more than six months when kept at $4^{\circ} \mathrm{C}$ to $10^{\circ} \mathrm{C}$.

The antigenicity of antigen is not always fixed but may be changeable by various. factors. 
1). Influence of $\mathrm{pH}$ upon rickettsia antigenicity;

A experiment has been carried out as to see how $\mathrm{pH}$ of the rickettsia suspension may influence upon the antigenicity. Both epidemic and murine antigens of known potency were centrifugalized at 7000 r.p.m. for half an hour and each supernatant was discarded. Each sediment was resuspended in buffered saline at $\mathrm{pH} 9.0,8.0,7.0,6.0$ and 5.0 in the original volume and preserved at $4^{\circ} \mathrm{C}$. After preservation for period of 24 hours, 3 days and 7 days each suspention at various $\mathrm{pH}$ was again centrifugalized at 7000 r.p.m. for half an hour and the sediment of each rickettsia-body was washed three times in buffered saline at ' $\mathrm{pH} 7.0$ and resuspended in the original volume for estimation of the antigenicity. The result revealed that the rickettsia antigenicity is found comparatively stable at $\mathrm{pH} 9.0-6.0$, and the tendency was observed towards spontaneous agglutination at $\mathrm{pH} 5.0$. After 24 hours preservation at $\mathrm{pH} 5.0$ a cross agglutination was observed and no more differentiation between the epidemic and murine typhus after 3 day preservation at the same $\mathrm{pH}$.

2). Thermal influence upon rickettsia antigenicity;

Rickettsia antigen should be stored at low temperature of 4 to $10^{\circ} \mathrm{C}$ but not frozen. An atempt was made to see if any fall in its potency may take place in such antigen when left exposed to warmer climate or got frozen by mistake. The antigenicity of two antigens of known potency was estimated after having kept at $28^{\circ} \mathrm{C}$ and $35^{\circ} \mathrm{C}$ for six days respectively. Results revealed that the thermal influence to such extent has not much been harmful and sometimes the antigen was still good but sometimes unstable having shown to decline to spontaneous agglutination.

Antigenicity both of the epidemic and the murine antigens was observed much ruined and disqualified when being frozen and melted in successions for ten times (Table 5). From foregoing experiments it should be emphasized that a rickettsia antigen

Table 5

Influence of freezing upon the antigenicity

\begin{tabular}{|c|c|c|c|c|c|c|c|c|}
\hline Serum Antiserum & \multicolumn{4}{|c|}{ antiepidemic typhus } & \multicolumn{4}{|c|}{ anti-murine typhus } \\
\hline Antigen & $1: 40$ & $1: 80$ & $1: 160$ & $1: 320$ & $1: 40$ & $1: 80$ & $1: 160$ & $1: 320$ \\
\hline before Epidemic & 3 & 2 & 2 & 0 & 0 & 0 & 0 & 0 \\
\hline after frozen & 3 & 0 & 0 & 0 & 0 & 0 & 0 & 0 \\
\hline before Murine & 0 & 0 & 0 & 0 & 2 & 2 & $2^{-}$ & 0 \\
\hline after frozen & 0 & 0 & 0 & 0 & \pm & 0 & 0 & 0 \\
\hline
\end{tabular}

should by no means be left under either high temperature or less than freezing point. but at a cold storage of 2 to $10^{\circ} \mathrm{C}$.

\section{SUMMARY}

The new method was described on the basis of fundamental experiments concernng a quantitative rickettsia agglutination test to be read bv naked eves with serum " 
diluted by the drop on hollow slide-glasses. This R.A.T. on the hollow slide-glass method is found available for diagnosis and differetiation of typhus fever from the other acute. infectious diseases and also the epidemic typhus from the murine provided one or two units of antigen is used of which antigenicity is to be estimated prior to practice and turbidity is suitable to be read by naked eyes. The test was found with the minimum experimental error and specific. It develops simultaneously with Weil-Felix reaction, if not a slightly later, and appears much earlier than complement fixation test. It arrives at its peak during the period of the 13 th to 15 th day after onset of disease. The antigen should be stored at $2-10^{\circ} \mathrm{C}$ and not frozen to avoid the loss of its antigenicity. Spontaneous agglutination of antigen is prevented by adding to antigen normal serum or gelatine 0.5 per cent in its concentration each.

\section{REFERENCE}

1) Rickette, H. t.: A micro-organism which apparenly has a specific Relationship to Rocky Mountain spotted fever, J.A.M.A. 52,379-380,1909

2) Ledingham, J.C.G.; Agglutination experiments with Trench fever Rickettsia, Lancet, 1, 1264 $-1266,1920$

3) Zinsser, H., and Castaneda, M.R.: Studies on typhus fever. IX On the serum reactions Mexican and European typhus Rickettsiae, J. Exp. Med. 56,455-466,1932

4) Kono, Michio: On the Rickettsia agglutination with $R$. prowazekii and R. manchuriae in the rabbit infected with the epidemic typhus, Tokyo Ijishinshi, No. 2923, 825-828, 1935. (In Japanese).

5) Castaneda, M.R., and Zia, S.H.: The antigen relationship between Proteus OX 19 and typhus rickettsia. J. Exp., Med., 58, 55-65, 1933.

6) Cox, H. E. : Use of yolk sac of developing chick embryos as medium for growing rickettsiae of Rocky Mountain spotted fever and typhus group. Pub., Health, Report. 53, 2241-2247, 1938.

7) Zinsser, H., and Castaneda, M.R.: Studies on typhusfever XI. A report on the properties of the serum of a horse immunized with killed formalinized rickettsiae. J. Exp. Med. 57,391 $-397,1933$.

8) Liu, P.Y., Zia, S.H., and Wang, K.C.: Serological studies on subjects vaccinated against typhus fever. Proc., Soc., Exp. Biol. \& Med., 38,682-684, 1936.

9) Castaneda, M.R.: Differentiation of typhus strains by slide agglutination test. J. Immunol., 50, 179-184, 1945.

10) Fitz-Patrick, F.K.: Vaccination of monky with agar-tissue of European rickettsiae. Proc. Soc. Exp. Biol. \& Med. 42, 217-218, 1939.

11) Hudson, N.P.: A macroscopic agglutination test with typhis rickettsiae prepared from infected rodent lung. J. Infect. Disease, 67, 227-231, 1940.

12) Plotz, et al,: The serological pattern in typhus fever. 1. Epidemic. Am. J. Hyg., 47, 150$165,1948$.

13) Nelson, C. T.: The serologic response in murine typhus as measured by the Weil-Felix, rickettsial complement fixin and rickettsial agglutination reactions. J. Lab., Clinic., Med., 32, 360-365, 1947.

14) Hammarstrom, E.: Research on the Weil-Felix reaction and the specific agglutination of rickettsias in patients suffering from exanthematic typhus. Bull., Offic. Internat. d'Hyg. Publique., 38, 270-273, 1946. (Trop. Diseases, Bull.)

15) Addison, B., et al.: The serological patern in typhus fever, 2. Murine. A. J. Hyg., 47, 166 $-176,1948$.

16) Packalen, T.: Rickettsial agglutination and complement fixation studies on epidemic typhus fever. Acta. Path. et Microb. Scand. 22, 573-592, 1945. (Trop. Diseases Bull.)

17) Giroud, P. and Jadin, J., : Phases of Maximum activity of specific antibodies in the case of experimental rickettsial infection. C. R. Soc. Biol., 141; 235-237, 1947. (Trop. Diseas. Bull.) 
18) Plotz, H., Bennett, B., Wertman, K., and Snyder, M.: Cross reacting typhus antibodies in Rocky Mountain spotted fever., Proc. Soc. Exp. Biol. \& Med. 57, 336, 1944.

19) Castaneda, M.R.: Experimental, pneumonia produced by typhus rickettsiae. Am. J. Path., 15, 467-473, 1939.

20) Kitaoka, Masami.: Simple rapid rickettsia agglutination on the slide-glass with R. prowazekii and typhi for differentiation from the epidemic typhus from the murine. Sogoigaku, 4, 6466, 1949. (in Japanese)

21) Fitz-Patrick, F. K.: Studies on rickettisa agglutination in typhus., J. Lab. \& Clinic. Med., 30, 577, 1945.

22) Kitaoka, Masami.: Preparation of antigen for complement fixation test in the typhus fever and estimation of its antigenicity., Nihonigaku, No. 3423, 181-184, 1948. (in Japanese) 